\title{
Influence of Intraseasonal-Interannual Oscillations on Tropical Cyclone Genesis in the Western North Pacific
}

\author{
JAU-MING CHEN \\ Department of Maritime Information and Technology, National Kaohsiung Marine University, Kaohsiung, Taiwan \\ CHING-HSUAN Wu \\ Department of Atmospheric Science, National Taiwan University, Taipei, Taiwan \\ Pei-Hsuan Chung \\ Department of History and Geography, University of Taipei, Taipei, Taiwan \\ CHUNG-Hsiung SuI \\ Department of Atmospheric Science, National Taiwan University, Taipei, Taiwan
}

(Manuscript received 20 September 2017, in final form 1 February 2018)

\begin{abstract}
Influences of intraseasonal-interannual oscillations on tropical cyclone (TC) genesis are evaluated by productivity of TC genesis $\left(P_{\mathrm{TCG}}\right)$ from the developing $\left(\mathrm{TC}_{d}\right)$ and nondeveloping $\left(\mathrm{TC}_{n}\right)$ precursory tropical disturbances (PTDs). A PTD is identified by a cyclonic tropical disturbance with a strong-enough intensity, a large-enough maximum center, and a long-enough lifespan. The percentage value of PTDs evolving into $\mathrm{TC}_{d}$ is defined as $P_{\text {TCG }}$. The analysis is performed over the western North Pacific (WNP) basin during the 19902014 warm season (May-September). The climatological $P_{\mathrm{TCG}}$ in the WNP basin is 0.35 . Counted in a common period, mean numbers of PTDs in the favorable and unfavorable conditions of climate oscillations for TC genesis [such as equatorial Rossby waves (ERWs), the Madden-Julian oscillation (MJO), and El Niño-Southern Oscillation (ENSO)], all exhibit a stable value close to the climatological mean [ 31 $\left.(100 \text { days })^{-1}\right]$. However, $P_{\mathrm{TCG}}$ increases (decreases) during the phases of positive-vorticity (negative-vorticity) ERWs, the active (inactive) MJO, and El Niño (La Niña) years. $P_{\text {TCG }}$ varies from 0.17 in the most unfavorable environment (La Niña, inactive MJO, and negative-vorticity ERW) to 0.56 in the most favorable environment (El Niño, active MJO, and positive-vorticity ERW). ERWs are most effective in modulating TC genesis, especially in the negative-vorticity phases. Overall, increased $P_{\mathrm{TCG}}$ is facilitated with strong and elongated 850-hPa relative vorticity overlapping a cyclonic shear line pattern, while decreased $P_{\mathrm{TCG}}$ is related to weak relative vorticity. Relative vorticity acts as the most important factor to modulate $P_{\mathrm{TCG}}$, when compared with vertical wind shear and 700-hPa relative humidity.
\end{abstract}

\section{Introduction}

Statistics of tropical cyclones (TC) reveals that the western North Pacific (WNP) hosts the largest TC genesis numbers (about $36 \%$ of the total number) among the global ocean basins (e.g., Gray 1968). During the warm season (May-September), the WNP features warm seawater and a monsoon trough, jointly providing excellent thermodynamic and dynamic conditions for TC genesis (e.g., Gray 1968; McBride 1995). Most TC

\footnotetext{
Corresponding author: Chung-Hsiung Sui, sui@as.ntu.edu.tw
}

genesis in the WNP occurs within a monsoon trough in company with several types of environmental flow patterns, such as a shear line pattern and a confluence region (Ritchie and Holland 1999; Yoshida and Ishikawa 2013; Molinari and Vollaro 2013). Mechanisms able to modulate intensity and locations of the monsoon trough and associated low-level dynamic variables have been found to modulate TC genesis in the WNP (e.g., Chen et al. 2006), such as the circulation changes associated with dynamics of El Niño-Southern Oscillation (ENSO; e.g., Rasmusson and Carpenter 1982; Rasmusson and Wallace 1983; Philander 1990) and the 30-60-day and 
10-20-day intraseasonal oscillations (ISOs) (e.g., Masunaga 2007). The 30-60-day ISO is dominated by the Madden-Julian oscillation (MJO) that was first identified by Madden and Julian $(1971,1972)$. The 10-20-day ISO (or quasi-biweekly oscillation) is essentially the equatorial Rossby wave (ERW) as shown in previous studies (e.g., Kikuchi and Wang 2009; Chen and Sui 2010). ENSO, the MJO, and ERWs all exert important impacts on TC genesis in the WNP.

During an El Niño event, the emergence of equatorial westerlies causes a monsoon trough to extend eastward, leading to more TC genesis in the southeast quadrant of the WNP and less TC genesis in the western section and the northwestern quadrant (e.g., Wu and Lau 1992; Lander 1994; Dong 1988; Wang and Chan 2002; Tao et al. 2012; Wang et al. 2013; Kim et al. 2013). Reduced TC genesis in the South China Sea (SCS) and the western section of the WNP is affected by anomalous suppressed convections following variability of the Walker circulation (e.g., Chan 1985; Li 1988). The favorable conditions for the above TC genesis include warmer ocean surface, enhanced convection, increased relative humidity in the lower and middle troposphere, reduced vertical wind shear, increased upper-level divergence, and low-level cyclonic vorticity (e.g., Camargo et al. 2007; Wu et al. 2012). For a La Niña year, the westward-retreated monsoon trough concurs with more TC genesis in the northwestern quadrant of the WNP but suppressed TC activity in the entire WNP from August to November (e.g., Chan 2000; Camargo et al. 2007; Chung and Li 2015).

For the influence of 30-60-day ISOs, the MJO may propagate eastward from the Indian Ocean across the WNP into the eastern Pacific (e.g., Madden and Julian 1994). Huang et al. (2011) found that the intraseasonal modulation on TC genesis in the subtropical WNP is mainly via variability of low-level vorticity that represents the major effect from a monsoon trough over there. A convectively enhanced (suppressed) phase of ISOs tends to be associated with more (less) TC genesis in the WNP and other TC basins (e.g., Kim et al. 2008; Barrett and Leslie 2009; Klotzbach 2014).

Many studies have recognized that ERWs are highly related to TC genesis (e.g., Frank and Roundy 2006; Schreck and Molinari 2009; Ching et al. 2010; Chen and Chou 2014). TC genesis associated with ERWs tends to occur in a strong enough ERW interacting with a favorable flow environment resembling a monsoon trough via a wave breaking of ERWs by which vorticity is organized on the scale of a TC (e.g., Gall and Frank 2010). When easterly vertical wind shear is present, the available potential energy is trapped in the lower troposphere. This acts to enhance wave amplitude and the possibility of TC genesis within the wave (e.g., Xie and Wang 1996).

The combined contributions of multiple tropical climate oscillations to TC genesis have also been analyzed. Chen and Chou (2014) examined the mixture of the MJO and tropical waves that causes a deeper monsoon trough that acts to intensify local circulation by increasing upward motion and low-level vorticity at the genesis location, and by modulating vertical wind shear. By examining the abundant TC genesis in June 2004, Ching et al. (2010) and Ching et al. (2015) demonstrated that both the MJO and ERWs have important modulation effects on TC genesis.

The precursory tropical disturbance (PTD) is commonly recognized as a synoptic-scale system featuring continuously developing deep convection or a strong cyclonic vortex. Using satellite data, Hennon et al. (2011) constructed a global climatology of tropical cloud clusters (TCCs) defined as the synoptic-scale areas with deep convection. A TCC can develop into a TC under favorable conditions. Hennon et al. (2013) examined the genesis productivity of TCCs into TCs for global ocean basins and found the highest productivity occurring over the WNP basin (about $12 \%)$. During El Niño years, TCC frequency increases (decreases) in the eastern (western) Pacific. However, TC genesis productivity shows no evident interannual variability associated with ENSO. Teng et al. (2014) further employed satellite data to investigate ENSO effects on TCC activity in the WNP basin. In their analysis, the overall genesis productivity of TCCs into TCs is about $27.3 \%$, while productivity in El Niño $(25.9 \%)$ and La Niña (28.6\%) years are relatively close, showing no noticeable ENSO impacts. Their analyses also showed that more TCs in the eastern (western) WNP during El Niño (La Niña) years mainly result from changes in TCC number, rather than changes in genesis productivity. In a different approach, Fu et al. (2012) employed reanalysis data to compare PTDs that are developing or not developing into TCs in the WNP and associated determining mechanisms. The PTD is represented by a strong-enough $\left(\geqq 10^{-5} \mathrm{~s}^{-1}\right.$ of $850-\mathrm{hPa}$ relative vorticity) and long-lasting ( $\geqq 72 \mathrm{~h}$ ) cyclonic vortex. They concluded that dynamic variables are more important than thermodynamic variables in facilitating the developments of PTDs into TCs in the WNP. This conclusion is consistent with that of Hennon et al. (2013) using TCC analysis. Their analyses indicate that the major dynamic parameters appear as large-scale vorticity and vertical wind shear.

The past studies mainly focused on the characteristics of resultant TC numbers in the WNP, while genesis productivity and associated modulations of background 
climate oscillations are less studied. TC genesis productivity in the WNP has been examined via TCC analysis by Hennon et al. (2013) and Teng et al. (2014). However, it has not been systematically examined via the approach of a vortex analysis. Moreover, impacts of the MJO and ERWs on TC genesis productivity in the WNP remain unexplored so far. The major purposes of this study are to analyze productivity of TC genesis $\left(P_{\mathrm{TCG}}\right)$ in the WNP via a vortex analysis using the reanalysis data; to use $P_{\mathrm{TCG}}$ as a more appropriate variable to show the influence on TC activity by ENSO, the MJO, ERWs, and their combined phases; and to reveal key environmental factors affecting TC genesis in the WNP on interannual and intraseasonal time scales. Results obtained from this study should advance our understanding for the developing processes and probability for TC genesis in the WNP on various time scales (e.g., climatological, intraseasonal, and interannual). This knowledge should help to improve short-term climate prediction tasks for TC activity in the WNP.

\section{Methodology and data}

A synoptic-scale tropical disturbance with a strong and persistent cyclonic vortex is a potential PTD to TC genesis (e.g., Lau and Lau 1990; Fu et al. 2007). A PTD is identified from the reanalysis data with three criteria modified from Fu et al. (2012) and Peng et al. (2012). The criteria are as follows: 1 ) a cyclonic vortex inferred from the 3-8-day filtered $850-\mathrm{hPa}$ relative vorticity (VOR850) has to reach the intensity of $10^{-5} \mathrm{~s}^{-1}, 2$ ) its vortex center stronger than $10^{-5} \mathrm{~s}^{-1}$ has to exceed $16000 \mathrm{~km}^{2}$, and 3) the above two criteria remain satisfied for 72 consecutive hours. Note that this study uses the size of maximum vorticity center instead of the circulation size. This change allows us to identify a vortex by only one variable (vorticity), rather than two variables (wind and vorticity) used previously. Our detected PTDs have a mean radius greater than $5^{\circ}$ (not shown), which satisfies the circulation size criterion with a radius greater than $400 \mathrm{~km}$ used by Fu et al. (2012) and Peng et al. (2012).

The identified PTDs are further separated into two categories: developing and nondeveloping TCs. The developing TCs $\left(\mathrm{TC}_{d}\right)$ have to match named TCs ( $\geqq 34 \mathrm{kt}$ ) in the best-track data of the Joint Typhoon Warning Center (JTWC). The remaining TCs are classified as the nondeveloping TCs $\left(\mathrm{TC}_{n}\right)$. A rapidly growing TC is possibly to develop from a tropical disturbance into a named TC within $72 \mathrm{~h}$. It is counted as a developing TC, instead of a nondeveloping TC. The location of a developing TC is defined at that revealed by the first record of that named TC in the
JTWC best-track data, while the location with the maximum intensity of the 3-8-day-filtered VOR850 is for a nondeveloping TC. The European Centre for Medium-Range Weather Forecasts (ECMWF) interim reanalysis (ERA-Interim) data (e.g., Dee et al. 2011) with a $0.75^{\circ} \times 0.75^{\circ}$ grid are used in the vortex analyses for TC genesis productivity over the WNP $\left(0^{\circ}-35^{\circ} \mathrm{N}\right.$, $\left.100^{\circ} \mathrm{E}-170^{\circ} \mathrm{W}\right)$. The analysis periods include TC-active warm seasons (May-September) during 1990-2014. This season is also the southwest monsoon season in the SCS and the western WNP.

\section{TC genesis productivity in the WNP}

To evaluate the relative importance of different climate oscillations on TC genesis, we need to count total $\mathrm{TC}_{d}$ and $\mathrm{TC}_{n}$ numbers in the period 1990-2014 and illustrate their spatial distributions in a specific spatial domain, say a $5^{\circ} \times 5^{\circ}$ box. In this study, we normalize $\mathrm{TC}_{d}$ and $\mathrm{TC}_{n}$ counts as numbers per 100 days (e.g., Liebmann et al. 1994). For the period of this study (1990-2014), there were 3825 warm-season days in which $420 \mathrm{TC}_{d}$ and $769 \mathrm{TC}_{n}$ were detected over the whole WNP basin. This gives $11.0 \mathrm{TC}_{d}, 20.1 \mathrm{TC}_{n}$, and a total of 31.1 PTDs per 100 days. The climatological value of productivity of TC genesis, $P_{\mathrm{TCG}}=\mathrm{TC}_{d} /\left(\mathrm{TC}_{d}+\mathrm{TC}_{n}\right)$, is 0.35 . It is larger than the 0.27 obtained from Teng et al.'s (2014) TCC analysis. This is probably due to a longer-lasting time being selected in this study $(72 \mathrm{~h})$ than in Teng et al. $(24 \mathrm{~h})$. Our analyses also show that $P_{\text {TCG }}$ decreases into $22.6 \%$ and $14.2 \%$ with a shorter lasting time of $48 \mathrm{~h}$ and $24 \mathrm{~h}$, respectively. In other words, a longer-lasting time results in a higher chance for a PTD developing into a named TC and thus a higher genesis productivity.

Spatial features associated with TC genesis productivity are depicted by numbers of $\mathrm{TC}_{d}, \mathrm{TC}_{n}$, and $P_{\mathrm{TCG}}$ averaged for each $5^{\circ} \times 5^{\circ}$ box. Spatial patterns of $\mathrm{TC}_{d}$ cases (Fig. 1a) exhibit maximum centers (larger than 0.35) extending southeastward from the eastern SCS across the Philippine Sea into the tropical WNP. This southeastward extension largely overlaps with climatological locations of a monsoon trough (e.g., Lander 1996; Chen et al. 2006). Total PTDs $\left(\mathrm{TC}_{d}+\mathrm{TC}_{n}\right)$ show a pattern similar to that of $\mathrm{TC}_{d}$, except at larger numbers (Fig. 1b). $P_{\text {TCG }}$ patterns (Fig. 1c) reveal that the development of a PTD into a TC is evidently facilitated in the western WNP over $10^{\circ}-20^{\circ} \mathrm{N}, 120^{\circ}-160^{\circ} \mathrm{E}$ with a $P_{\text {TCG }}$ value of $0.4-0.65$, followed by the regions east of $160^{\circ} \mathrm{E}$ with a $P_{\mathrm{TCG}}$ value about $0.35-0.5$. $P_{\mathrm{TCG}}$ values in boxes having fewer than two $\mathrm{TC}_{d}$ cases are not shown because of an insufficient representation of TC genesis. 


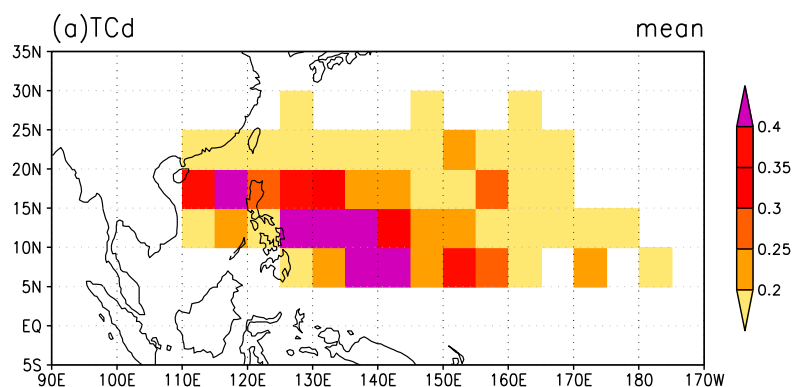

(b) $T C d+T C n$ mean
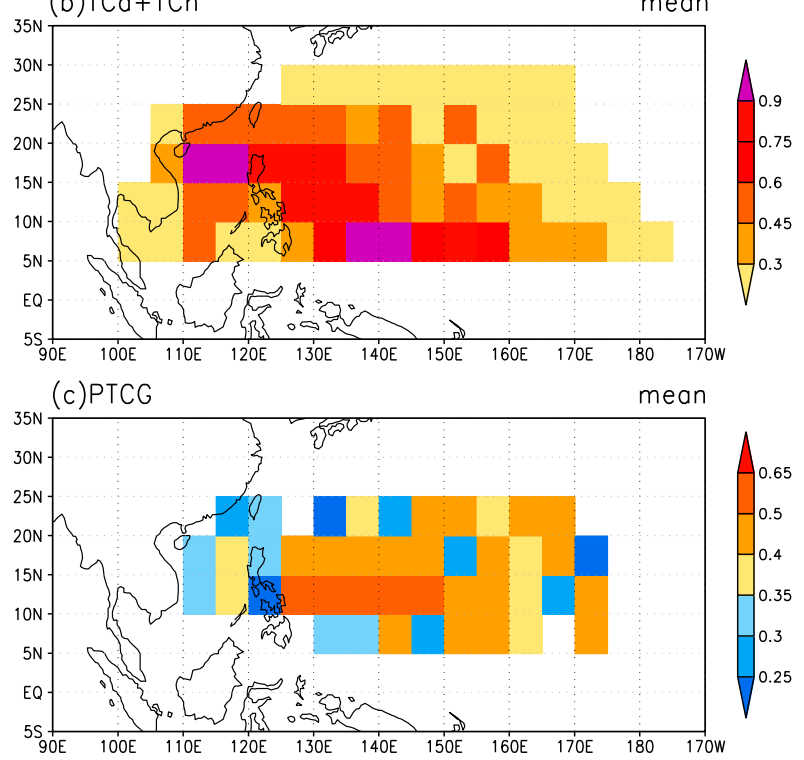

FIG. 1. Climatological values every 100 days for (a) developing cases, (b) total precursory tropical disturbances, and (c) productivity of TC genesis $\left(P_{\mathrm{TCG}}\right)$ for each $5^{\circ} \times 5^{\circ}$ box in the WNP.

\section{TC genesis productivity and ENSO}

Impacts from the large-scale environment variability associated with ENSO and the MJO on TC genesis productivity are studied in a spatial domain covering the entire WNP basin. The oceanic Niño index (ONI; e.g., Xue et al. 2003) represented by the Niño-3.4 sea surface temperature (SST) anomalies $\left(5^{\circ} \mathrm{S}-5^{\circ} \mathrm{N}, 120^{\circ}-170^{\circ} \mathrm{W}\right)$ from the Climate Prediction Center at the National Oceanic and Atmospheric Administration (NOAA) is used to separate ENSO cases into the warm, cold, and normal years. An El Niño (a La Niña) year that represents a warm (cold) ENSO case needs to have an averaged ONI value larger (smaller) than $0.3^{\circ} \mathrm{C}$ $\left(-0.3^{\circ} \mathrm{C}\right)$ during May-September and $0.5^{\circ} \mathrm{C}\left(-0.5^{\circ} \mathrm{C}\right)$ in the succeeding winter. The remaining cases are classified as the normal years. These definitions result in to six El Niño years (1991, 1994, 1997, 2002, 2004, and 2009), seven La Niña years (1998, 1999, 2000, 2007, 2008, 2010, and 2011), and 12 normal years. As shown in Table 1,
TABLE 1. Normalized numbers of $\mathrm{TC}_{d}$ and $\mathrm{TC}_{n}$ per 100 days and $P_{\text {TCG }}$ in the WNP basin for climatology, interannual oscillations (El Niño, La Niña, normal) years, the MJO (active, inactive) phases, and ERWs (positive vorticity, negative vorticity). $P_{\text {TCG }}$ values significant at the $0.1,0.05$, and 0.01 levels of a Student's $t$ test are marked with,,++++++ , respectively. $\mathrm{TC}_{d}$ and $\mathrm{TC}_{n}$ numbers significant at the $0.1,0.05,0.01$ levels of a $Z$ test are marked with $*, * *, * * *$, respectively.

\begin{tabular}{lllll}
\hline \multicolumn{1}{c}{ Type } & \multicolumn{1}{c}{$\left(\mathrm{TC}_{d}, \mathrm{TC}_{n}\right)$} & $\left(\mathrm{TC}_{d}+\mathrm{TC}_{n}\right)$ & \multicolumn{1}{c}{$P_{\mathrm{TCG}}$} \\
\hline Climatology & $(11.0,20.1)$ & 31.1 & 31.1 & 0.35 \\
El Niño years & $(12.4,18.6)$ & 31.0 & 31.0 & $0.40^{+}$ \\
La Niña years & $(9.3,21.7)$ & 31.0 & & $0.30^{+++}$ \\
Normal years & $(11.2,19.9)$ & 31.1 & 31.1 & 0.36 \\
Active MJO & $\left(13.7^{* * *}, 18.7\right)$ & 32.4 & 31.4 & 0.42 \\
Inactive MJO & $\left(9.6^{* *}, 20.8\right)$ & 30.4 & & 0.32 \\
Positive vorticity & $(16.3,22.1)$ & 38.4 & 31.4 & 0.43 \\
$\quad$ & & & & \\
$\quad$ ERW & & 24.4 & & 0.25 \\
$\quad$ ERative vorticity & $(6.1,18.3)$ & & & \\
\hline
\end{tabular}

$\mathrm{TC}_{d}$ and $\mathrm{TC}_{n}$ numbers per 100 days during the normal years are 11.2 and 19.9 , respectively. The $P_{\mathrm{TCG}}$ is 0.36 , close to the climatological value (0.35). Both El Niño and La Niña years have the same total disturbance number of 31 per 100 days. Nevertheless, $\mathrm{TC}_{d}$ cases are 12.4 in El Niño years and 9.3 in La Niña years. $P_{\text {TCG }}$ increases in El Niño years $(0.40)$ and decreases in La Niña years (0.30). Both $P_{\mathrm{TCG}}$ values are statistically significant at the 0.1 level of a Student's $t$ test. It appears that ENSO has significant impacts on $P_{\text {TCG }}$ in the WNP, but not on the total number of PTDs.

A box difference index (BDI) proposed by Peng et al. (2012) and Fu et al. (2012) is adopted to quantitatively measure the relative importance of environmental variables in differentiating $\mathrm{TC}_{d}$ and $\mathrm{TC}_{n}$ cases, as well as effects on the $P_{\mathrm{TCG}}$. The BDI is computed as $\left(M_{\mathrm{TCd}}-\right.$ $\left.M_{\mathrm{TCn}}\right) /\left(\mathrm{STD}_{\mathrm{TCd}}+\mathrm{STD}_{\mathrm{TCn}}\right)$, where $M$ and STD represent the variable mean and standard deviation of $\mathrm{TC}_{d}$ or $\mathrm{TC}_{n}$ cases, respectively. Environmental variables affecting the potential of TC genesis are evaluated from their 30-day low-pass-filtered components averaged from a $3^{\circ} \times 3^{\circ}$ box within $1.5^{\circ}$ from the center of each $\mathrm{TC}_{d}$ or $\mathrm{TC}_{n}$ case. The above low-pass components include both intraseasonal and interannual signals and allow us to measure the modulations of ENSO, the $\mathrm{MJO}$, and their combined phases on TC genesis with a unified variable. A variable with greater BDI amplitudes indicates its more important role in affecting TC genesis. The analyzed environmental variables important to TC genesis include VOR850, 700-hPa relative humidity (RH700), and vertical wind shear of total winds between 200 and $850 \mathrm{hPa}$ (VWS) (e.g., Chia and Ropelewski 2002; Wang and Chan 2002; Frank and Roundy 2006; Camargo et al. 2007). As shown in Table 2, BDI amplitudes of VOR850 for El Niño and La Niña 
TABLE 2. Composite statistics associated with the box difference index (BDI) analysis (see the texts) for 850-hPa relative vorticity (VOR850), 700-hPa relative humidity (RH700), and vertical shear of total winds (VWS). The difference values $\left(M_{\mathrm{TCd}}-M_{\mathrm{TCn}}\right)$ significant at the $0.1,0.05$, and 0.01 levels of a Student's $t$ test are marked with *,**, and ***, respectively.

\begin{tabular}{|c|c|c|c|c|c|c|}
\hline \multirow[b]{2}{*}{ Type } & \multicolumn{2}{|l|}{ VOR850 } & \multicolumn{2}{|l|}{ RH700 } & \multirow{2}{*}{$\frac{\mathrm{VWS}}{\left(M_{\mathrm{TCd}}, M_{\mathrm{TCn}}\right) M_{\mathrm{TCd}}-M_{\mathrm{TCn}}}$} & \multirow[b]{2}{*}{ BDI } \\
\hline & $\left(M_{\mathrm{TCd}}, M_{\mathrm{TCn}}\right) M_{\mathrm{TCd}}-M_{\mathrm{TCn}}$ & BDI & $\left(M_{\mathrm{TCd}}, M_{\mathrm{TCn}}\right) M_{\mathrm{TCd}}-M_{\mathrm{TCn}}$ & BDI & & \\
\hline El Niño & $(9.85,4.40) 5.45^{* * *}$ & 0.43 & $(71.1,65.1) 6.0^{* * *}$ & 0.41 & $(12.5,13.2)-0.7$ & -0.09 \\
\hline La Niña & $(7.20,1.94) 5.26^{* * *}$ & 0.40 & $(69.8,67.1) 2.7 * * *$ & 0.19 & $(12.6,13.2)-0.6$ & -0.09 \\
\hline Active MJO & $(8.95,4.52) 4.03 * * *$ & 0.31 & $(71.5,67.9) 3.6^{* * *}$ & 0.25 & $(12.5,13.6)-1.1 * * *$ & -0.15 \\
\hline Inactive $\mathrm{MJO}$ & $(7.20,2.08) 5.12 * * *$ & 0.42 & $(69.0,65.4) 3.6^{* * *}$ & 0.25 & $(11.8,12.6)-0.8 * * *$ & -0.11 \\
\hline
\end{tabular}

years (0.43-0.44) are larger than those of RH700 (0.19$0.41)$ and VWS $(-0.09)$. Differences of VOR850 and RH700 between $M_{\mathrm{TCd}}$ and $M_{\mathrm{TCn}}$ are statistically significant for both El Niño and La Niña years. Overall, VOR850 plays a more important role than $\mathrm{RH} 700$ and VWS in affecting $P_{\text {TCG }}$ during ENSO years in the WNP.

The spatial patterns of $P_{\mathrm{TCG}}$ and the associated environmental variables are shown in Fig. 2. Composite $P_{\text {TCG }}$ patterns in El Niño years (Fig. 2a) elongate southeastward from the SCS into the tropical eastern WNP with a maximum center over $5^{\circ}-15^{\circ} \mathrm{N}, 130^{\circ}-155^{\circ} \mathrm{E}$. In La Niña years, $P_{\text {TCG }}$ concentrates westward with a maximum center over $10^{\circ}-20^{\circ} \mathrm{N}, 125^{\circ}-145^{\circ} \mathrm{E}$ (Fig. $2 \mathrm{~b}$ ). The environmental variables are illustrated by composite differences between El Niño and La Niña years (El Niño-La Niña). The differences of VOR850 and $850-\mathrm{hPa}$ wind (V850) reveal that the elongated $P_{\mathrm{TCG}}$ patterns in El Niño years are associated with cyclonic shear and positive VOR850 anomalies across the tropical WNP (Fig. 2c). These features concur with the eastward displacement of a monsoon trough and TC genesis locations (e.g., Lander 1994; Wang and Chan 2002), yielding increased $P_{\mathrm{TCG}}$ in the southeastern WNP over $5^{\circ}-15^{\circ} \mathrm{N}, 145^{\circ}-175^{\circ} \mathrm{E}$. In this southeastern region, increased $P_{\mathrm{TCG}}$ during El Niño years is also associated with positive RH700 anomalies (Fig. 2d) and negative VWS anomalies (Fig. 2e). Increased humidity and weakened vertical wind shear provide positive contributions to the southeastward shift of TC genesis locations (e.g., Wang and Chan 2002; Camargo et al. 2007; Kim et al. 2013), as well as an increase in $P_{\text {TCG }}$.

\section{TC genesis productivity and the MJO}

The MJO's influence on $P_{\mathrm{TCG}}$ is evaluated by contrasting their differences in the active and inactive phases of the MJOs. To categorize these phases, a convective $\mathrm{MJO}$ index is constructed from the NOAA daily outgoing longwave radiation (OLR) data with a $2.5^{\circ} \times$ $2.5^{\circ}$ resolution (e.g., Liebmann and Smith 1996). The daily OLR data in May-September of each year are filtered to reserve temporal components of 30-90 days and spatial components of wavenumbers $0-5$. A MJO index is measured as the filtered OLR value averaged from the tropical WNP domain of $0^{\circ}-15^{\circ} \mathrm{N}, 110^{\circ}-170^{\circ} \mathrm{E}$. The active MJO phases with enhanced convection are defined as the period of the negative phases of the MJO index except the first three and last three days of the period. The remaining period is categorized as the inactive MJO phases with suppressed convection. A comparison of our MJO index with the real-time multivariate MJO (RMM) index constructed by Wheeler and Hendon (2004) reveals that our active MJO phases correspond to phases 4,5 , and 6 of RMM, featuring major convective activity over the Maritime Continents and the WNP. The active MJO phases in this study spatially correspond well with the major TC-genesis region in the WNP. In case a burst of TCs occurs in a fraction of the intraseasonal time scale falling in one of the MJO active phases, it can be reasonably regarded as TC genesis in a favorable environment under the MJO influence. The MJO phases from our index are thus suitable for analyzing impacts of the MJO on TC genesis productivity in the WNP basin.

Table 1 shows that $13.7 \mathrm{TC}_{d}$ and $18.7 \mathrm{TC}_{n}$ cases occur in the active MJO phases every 100 days, while there are 9.6 $\mathrm{TC}_{d}$ and $20.8 \mathrm{TC}_{n}$ cases for the inactive MJO phases. The averaged total disturbance number for the active (32.4) and inactive (30.4) phases is 31.4 , comparable to the climatological value (31.1). A $Z$ test (Hall et al. 2001; $\mathrm{Li}$ et al. 2012) discloses that increased (decreased) $\mathrm{TC}_{d}$ cases during the active (inactive) MJO phases are statistically significant at the 0.05 level, leading to an increased (a decreased) $P_{\mathrm{TCG}}$ value of 0.42 (0.32). BDI analyses in Table 2 reveal that $M_{\mathrm{TCd}}-M_{\mathrm{TCn}}$ values of VOR850, RH700, and VWS are statistically significant for both active and inactive MJO phases. However, BDI amplitudes are the largest for VOR850 (0.31-0.42), followed by RH700 (0.25) and VWS (about -0.15 ). VOR850 appears as the dominant variable in affecting $P_{\text {TCG }}$ during the MJO phases.

Composite $P_{\text {TCG }}$ patterns for the active (Fig. 3a) and inactive (Fig. 3b) MJO phases both exhibit an elongated distribution across the tropical WNP, except a generally 
(a)PTCG EI Nino

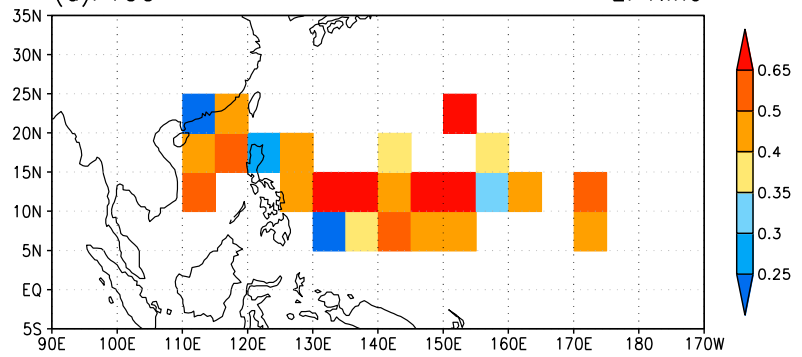

(b)PTCG La Nina
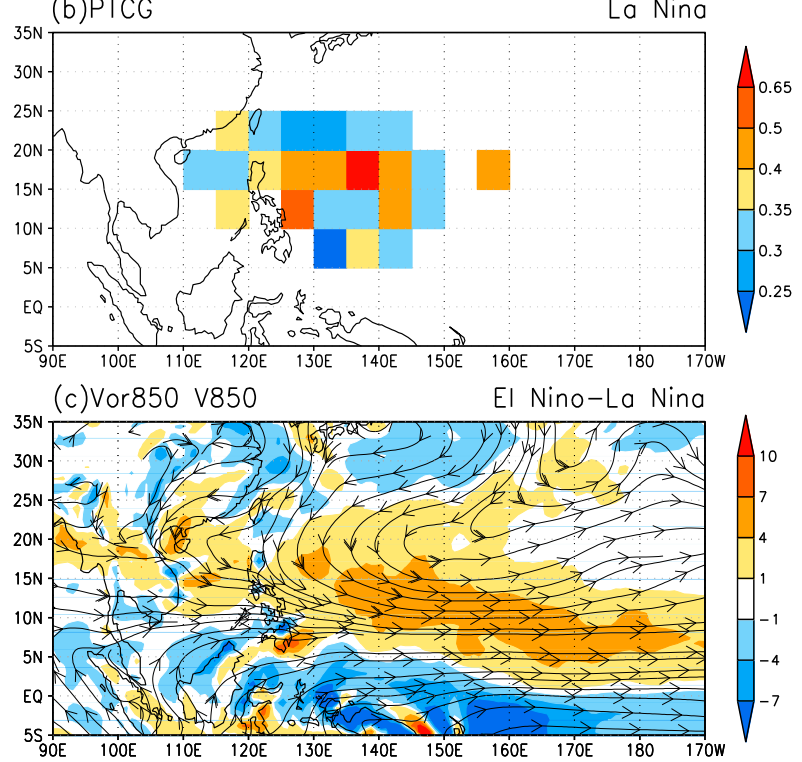

(d) $\mathrm{RH} 700 \quad$ El Nino-La Nina
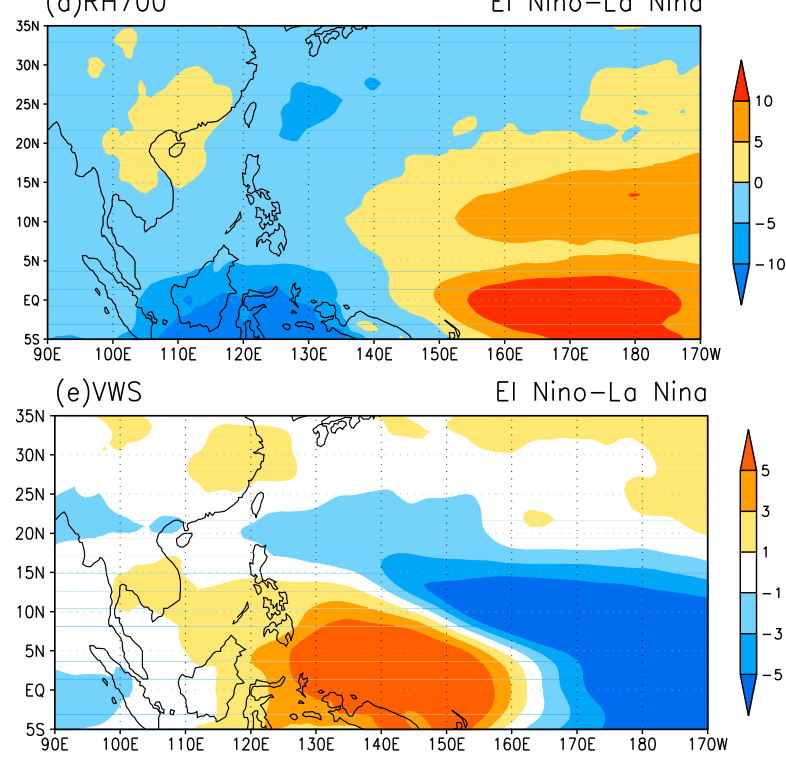

FIG. 2. Composite $P_{\text {TCG }}$ patterns for (a) El Niño and (b) La Niña years. Composite differences (El Niño-La Niña) of (c) 850-hPa relative vorticity and flow, (d) $700-\mathrm{hPa}$ relative humidity, and (e) vertical wind shear of total winds. Units are $\mathrm{s}^{-1}$ in (c), \% in (d), and $\mathrm{m} \mathrm{s}^{-1}$ in (e). larger value in the active phases than the inactive phases. The MJO phases selected in this study correspond to an eastward propagation of enhanced or suppressed convection across the WNP. This propagation feature tends to affect TC genesis productivity across the entire WNP basin. To the east of $150^{\circ} \mathrm{E}$, the major center stretches southeastward to the south of $15^{\circ} \mathrm{N}$ in the active phases, but northeastward to the north of $15^{\circ} \mathrm{N}$ in the inactive phases. This is consistent with the MJO modulation effects on TC genesis found by Kim et al. (2008). For the environmental variables, composite differences (activeinactive) of VOR850 and V850 (Fig. 3c) show that a cyclonic circulation and positive VOR850 anomalies result in larger $P_{\mathrm{TCG}}$ to the west of $150^{\circ} \mathrm{E}$ in the active phases. To the east of $150^{\circ} \mathrm{E}$, decreased (increased) humidity as indicated by negative (positive) RH700 anomalies (Fig. 3d) causes reduced (enhanced) $P_{\text {TCG }}$ to the north (south) of $15^{\circ} \mathrm{N}$. The VWS differences (Fig. 3e) show positive anomalies to the east of $150^{\circ} \mathrm{E}$, revealing its generally suppressing (enhancing) effects on $P_{\mathrm{TCG}}$ during the active (inactive) MJO phases. It is clear that favorable impacts on TC genesis productivity by the MJO are given by VOR850 in the western WNP to the west of $150^{\circ} \mathrm{E}$, while unfavorable impacts given by VWS are strong to the east of $150^{\circ} \mathrm{E}$ (Fig. 3e). Humidity also provides regional impacts on $P_{\mathrm{TCG}}$, favorable in the regions north of $15^{\circ} \mathrm{N}$ and unfavorable in the regions south of $15^{\circ} \mathrm{N}$ during the active phases.

\section{Combined effects of ENSO and the MJO}

Both the MJO and ENSO affect the WNP TC activity in a basin scale. Their joint effects on $P_{\text {TCG }}$ patterns are examined via four combined phases: El Niño-active MJO (EN-aM), El Niño-inactive MJO (EN-iM), La Niña-active MJO (LN-aM), and La Niña-inactive MJO (LN-iM). As shown in Table $3, \mathrm{TC}_{d}(100 \text { days })^{-1}$ is 16.3 for an $\mathrm{EN}$-aM phase and only 8.3 for a $\mathrm{LN}$-iM phase. The value becomes 10.0 for an EN-iM phase and 11.1 for a $\mathrm{LN}-\mathrm{aM}$ phase, with no significant difference from the climatological value of 11.0. Consequently, an evident increase (decrease) in $P_{\mathrm{TCG}}$ from the climatological mean (0.35 in Table 1) results in a value of $0.47(0.26)$ in an EN-aM (a LN-iM) phase, while a value closer to climatological value in the EN-iM (0.35) and $\mathrm{LN}-\mathrm{aM}(0.38)$ phases. As analyzed previously, El Niño and the active MJO phases tend to enhance $P_{\mathrm{TCG}}$, while La Niña and the inactive MJO phases act to suppress $P_{\mathrm{TCG}}$. The combination effects in the EN-aM (LN-iM) phases thus provide double positive (negative) impacts for TC genesis productivity. Similarly, effects of ENSO and the MJO compensate each other in the $\mathrm{EN}-\mathrm{iM}$ and $\mathrm{LN}-\mathrm{aM}$ phases, leading to a $P_{\mathrm{TCG}}$ value close to the climatological mean. 

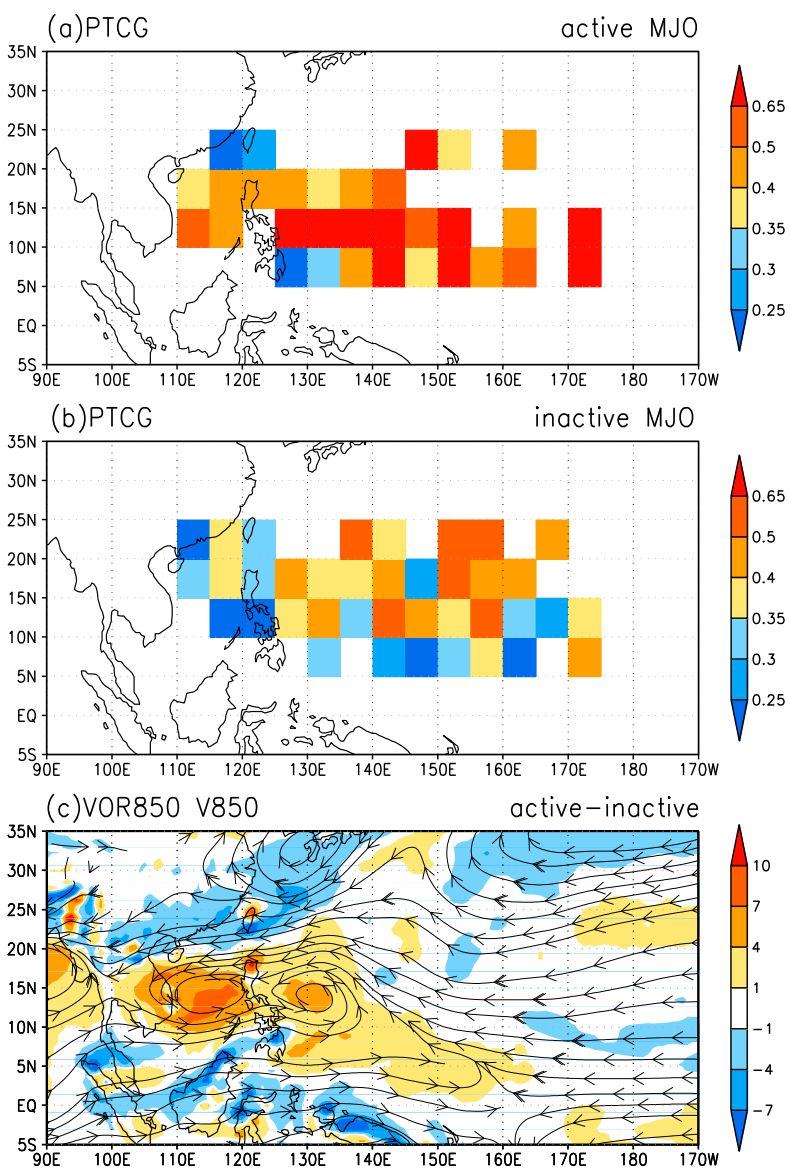

(d) $\mathrm{RH} 700$
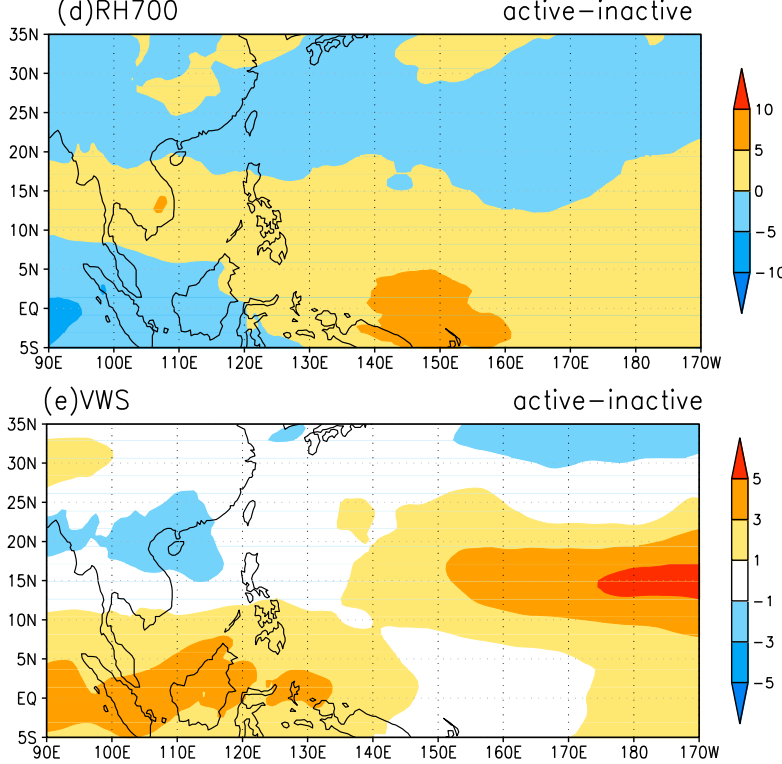

FIG. 3. Composite $P_{\text {TCG }}$ patterns for the (a) active and (b) inactive MJO phases. Composite differences (active-inactive) of (c) 850-hPa relative vorticity and flow, (d) 700-hPa relative humidity, and (e) vertical wind shear of total winds. Units are $\mathrm{s}^{-1}$ in (c), \% in (d), and $\mathrm{m} \mathrm{s}^{-1}$ in (e).
With the highest and lowest $P_{\mathrm{TCG}}$ values, doubly strengthened effects from ENSO and the MJO on TC genesis productivity are examined via a comparison between the EN-aM and $\mathrm{LN}$-iM phases. Their composite $P_{\text {TCG }}$ patterns exhibit an elongated pattern across the tropical WNP in the EN-aM phases (Fig. 4a), but a confined pattern in the western WNP in the LN-iM phases (Fig. 4b). The above zonal contrasts resemble those between El Niño and La Niña in Fig. 2, rather than between the active and inactive MJO phases in Fig. 3 . This pattern contrast reveals that ENSO seems to have more influence on $P_{\mathrm{TCG}}$ patterns than the MJO in the combined phases. Composite differences of VOR850 and V850 for the EN-aM and $\mathrm{LN}$-iM phases (EN-aM$\mathrm{LN}$-iM) (Fig. 4c) possess a cyclonic shear overlapping elongated positive VOR850 anomalies extending from the SCS eastward up to $180^{\circ}$, similar to the composite difference patterns of ENSO in Fig. 2c. In this eastwardextending region east of $150^{\circ} \mathrm{E}$, there are positive difference anomalies of RH700 (Fig. 4d) to the south of $15^{\circ} \mathrm{N}$ that accompany negative VWS anomalies (Fig. 4e). The above differences of RH700 and VWS between the $\mathrm{EN}-\mathrm{aM}$ and $\mathrm{LN}-\mathrm{iM}$ phases resemble the differences between El Niño and La Niña years (see Figs. $2 \mathrm{~d}$ and $2 \mathrm{e}$ ), but are evidently different from the differences between the active and inactive MJO phases (see Figs. $3 \mathrm{~d}$ and $3 \mathrm{e}$ ). In the region west of $150^{\circ} \mathrm{E}, \mathrm{RH} 700$ difference anomalies shows positive patterns to provide favorable conditions for TC genesis productivity, while positive VWS anomalies provide negative effects for genesis productivity. The above difference analyses of $P_{\mathrm{TCG}}$ and environmental variables reveal that VOR850 and RH700 provide positive contributions to modulate $P_{\text {TCG }}$ in the WNP during the combined ENSO-MJO phases. Moreover, ENSO plays a more important role than the MJO in the modulation processes of the combined phases.

\section{TC genesis productivity and ERW}

In this study, an ERW is extracted from space-timefiltered (Wheeler and Kiladis 1999) ERA-Interim reanalysis data. It contains temporal components of 10-30 days and spatial components of the westwardmoving wavenumbers $1-10$. We separated $\mathrm{TC}_{d}$ and $\mathrm{TC}_{n}$ into two ERW types: positive-vorticity ERW (pvERW) and negative-vorticity ERW (nvERW). The separation is determined by the sign of a $5^{\circ} \times 5^{\circ}$ mean background VOR850 at a TC's center. A domain mean statistics of TC numbers and $P_{\mathrm{TCG}}$ is shown in Table 1 . There are $295 \mathrm{TC}_{d}$ and $398 \mathrm{TC}_{n}$ in the pvERW type and $114 \mathrm{TC}_{d}$ and $338 \mathrm{TC}_{n}$ in the nvERW type. Unlike the MJO or ENSO oscillations that influence the entire WNP 
TABLE 3. $\mathrm{TC}_{d} / \mathrm{TC}_{n}$ numbers per 100 days and $P_{\mathrm{TCG}}$ in the WNP basin corresponding to different combinations of favorable and unfavorable phases of climate oscillations [i.e., (El Niño, La Niña, normal) $\times($ active MJO, inactive MJO) $\times($ positive-vorticity ERW, negative-vorticity ERW)]. $P_{\text {TCG }}$ values in favorable (unfavorable) phases are in bold (italic). The most favorable and unfavorable phases are in both bold and italic.

\begin{tabular}{|c|c|c|c|c|c|c|c|}
\hline & & \multicolumn{2}{|c|}{ El Niño } & \multicolumn{2}{|c|}{ La Niña } & \multicolumn{2}{|c|}{ Normal } \\
\hline & & aMJO & iMJO & aMJO & iMJO & aMJO & iMJO \\
\hline ENSO-MJO-ERW combination & $\begin{array}{l}\text { Positive vorticity ERW } \\
\text { Negative vorticity ERW }\end{array}$ & $\begin{array}{l}23.1 / 17.9 \\
\mathbf{0 . 5 6} \\
9.6 / 19.2 \\
\mathbf{0 . 3 3}\end{array}$ & $\begin{array}{l}15.1 / 20.1 \\
\mathbf{0 . 4 4} \\
4.9 / 17.0 \\
0.23\end{array}$ & $\begin{array}{l}17.2 / 18.2 \\
\mathbf{0 . 4 9} \\
5.0 / 17.6 \\
0.22\end{array}$ & $\begin{array}{l}11.9 / 24.5 \\
0.33 \\
4.7 / 23.1 \\
\boldsymbol{0 . 1 7}\end{array}$ & $\begin{array}{l}21.2 / 21.2 \\
\mathbf{0 . 5 0} \\
7.5 / 17.6 \\
0.30\end{array}$ & $\begin{array}{l}13.8 / 24.1 \\
0.36 \\
6.3 / 16.1 \\
0.28\end{array}$ \\
\hline ENSO-MJO combination & & $\begin{array}{c}16.3 / 18.9 \\
0.47\end{array}$ & $\begin{array}{c}10.0 / 18.5 \\
0.35\end{array}$ & $\begin{array}{c}11.1 / 17.4 \\
0.38\end{array}$ & $\begin{array}{l}8.3 / 24.2 \\
0.26\end{array}$ & $\begin{array}{c}14.1 / 19.4 \\
0.43\end{array}$ & $\begin{array}{c}10.0 / 20.0 \\
0.33\end{array}$ \\
\hline
\end{tabular}

domain uniformly at any given day because of their planetary spatial scales, the wavelength of ERWs is smaller than the WNP's zonal width. We cannot assume the entire WNP is in a pvERW or nvERW condition like in ENSO conditions or the MJO phases. To compare TC statistics in ERWs with that of ENSO and the MJO properly, we calculate occurrence frequency of daily mean vorticity averaged over each $5^{\circ} \times 5^{\circ}$ box to normalize TC numbers for the pvERW and nvERW types in the WNP. The normalized $\mathrm{TC}_{d}\left(\mathrm{TC}_{n}\right)$ over the whole WNP domain per 100 days is 16.3 (22.1) in the pvERW type and 6.1 (18.3) in the nvERW type. The corresponding $P_{\mathrm{TCG}}$ for the pvERW type is 0.43 , compatible with El Niño and the active MJO. However, $P_{\mathrm{TCG}}$ for the nvERW type is only 0.25 , notably lower than that of La Niña (0.30) and the inactive MJO (0.32). This suggests that the inhibition effect on TC genesis by negative vorticity of ERWs is stronger than that by La Niña and the inactive MJO. Spatial patterns of $P_{\mathrm{TCG}}$ of the pvERW and nvERW types are shown in Fig. 5. In general, the degree of enhanced $P_{\text {TCG }}$ above climatology by the pvERW type is comparable to that by ENSO and the active MJO, but the area of influence by the pvERW type in the WNP extends north of $20^{\circ} \mathrm{N}$, clearly broader than the influence area of the other climate oscillations considered here. On the other hand, $P_{\mathrm{TCG}}$ distribution in the nvERW type shows a dipole pattern, higher (lower) $P_{\mathrm{TCG}}$ in the eastern (western) part of the WNP separated by $150^{\circ} \mathrm{E}$.

Composite ERW flows relative to all $\mathrm{TC}_{d}$ centers are shown in Fig. 6. For the pvERW type, the composite $\mathrm{TC}_{d}$ center is located near the center of cyclonic vorticity at $850 \mathrm{hPa}$ (Fig. 6b) and anticyclonic divergent flows at $150 \mathrm{hPa}$ (Fig. 6a). The center of low-level cyclonic flow and upper-level divergent flow coincides with enhanced convection (Fig. 6c). Figures 6a-c show that the development of $\mathrm{TC}_{d}$ in ERWs produces a strong convection-coupled vertical structure of the first baroclinic mode and twin cyclone (anticyclonic) wave trains with the northern portion (north of $10^{\circ} \mathrm{N}$ ) stronger than the southern portion of the wave train. For the nvERW type, the composite $\mathrm{TC}_{d}$ center is located in the southwesterly flows between a cyclonic circulation and an anticyclonic circulation of ERWs at $850 \mathrm{hPa}$ (Fig. 6e) and a reversed circulation pattern at $150 \mathrm{hPa}$ (Fig. 6d). The composite ERW circulation is SW-NE oriented and convection appears to shift $1 / 4$ wavelength eastward of the low-level cyclonic center (Fig. 6f). The composite wavelength of both pvERW and nvERW types is about $50^{\circ}-60^{\circ}$. The overall composite structure of the nvERW type is similar to the Rossby wave destabilized by easterly shear and convective heating (Xie and Wang 1996; Chatterjee and Goswami 2004).

The composite structure of the pvERW type relative to $\mathrm{TC}_{n}$ (figures not shown) is similar to the structure shown in Figs. 6a-c but weaker in magnitude. The composite structure of the nvERW type relative to $\mathrm{TC}_{n}$ shows a reversed pattern of Figs. 6a-c. The composite result of the ERW structure discussed above leads us to propose the following arguments that deserve further investigations. First, there exists an unstable ERW mode with a northeast-southwest horizontal tilt in the nvERW type that may provide energy for TC genesis $\left(\mathrm{TC}_{d}\right)$. Second, the degree of coupling between TCs and ERWs decides the chance of TC genesis as suggested from the pvERW structure relative to $\mathrm{TC}_{d}$ and $\mathrm{TC}_{n}$. Third, lowlevel anticyclonic vorticity of ERWs effectively inhibits TC genesis.

Composite ERW structures relative to TCs have been discussed in previous studies (e.g., Frank and Roundy 2006; Chen and Chou 2014). Their composite studies are formed for all ERWs corresponding to TCs $\left(\mathrm{TC}_{d}\right.$ in this study) without separation into the pvERW and nvERW types. Their composite TC center is located southeast of a low-level cyclonic circulation where strong southwesterly flows prevail, which can be reproduced by forming a weighted mean of the composite structure of the pvERW and nvERW types in Fig. 6. 

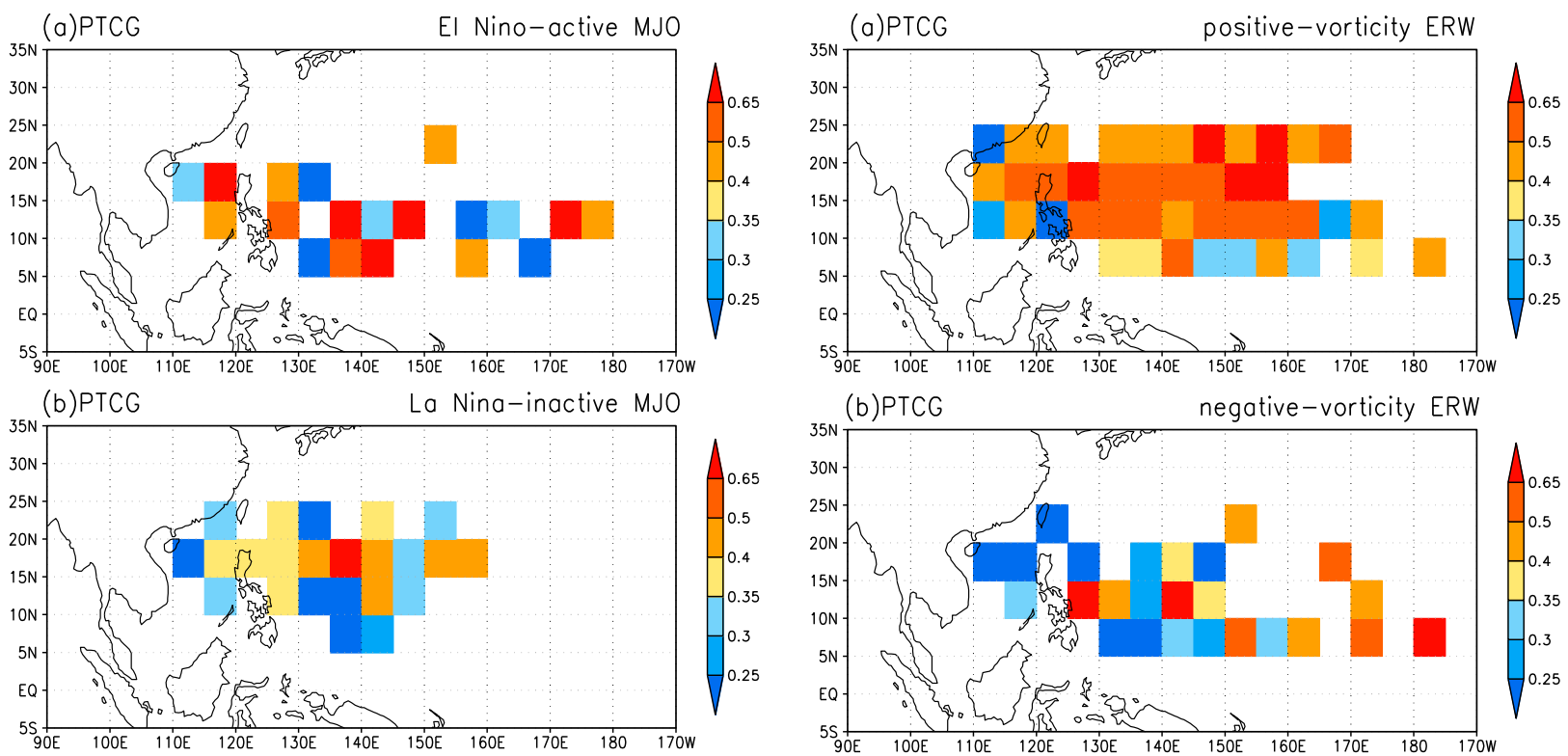

(b) PTCG negative-vorticity ERW

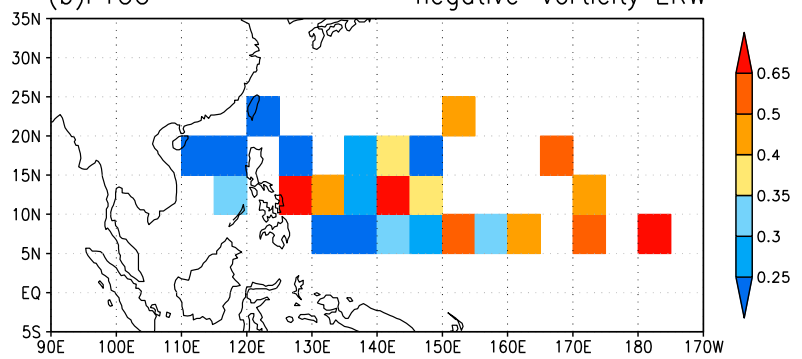

(c) V0R850 V850

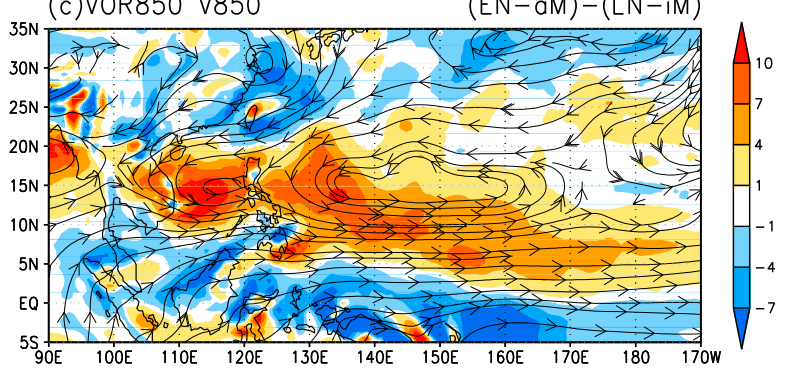

(d) $\mathrm{RH} 700$

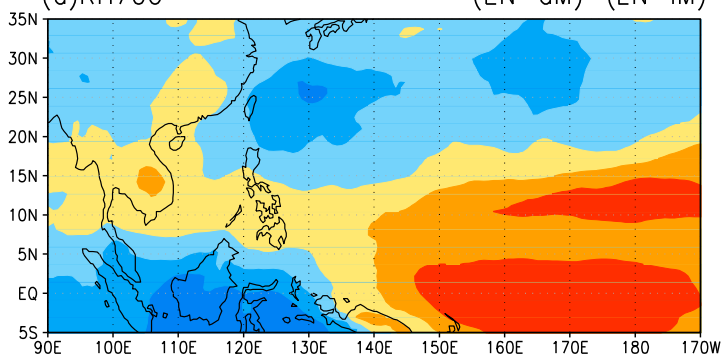

(e)VWS

$(E N-a M)-(L N-i M)$

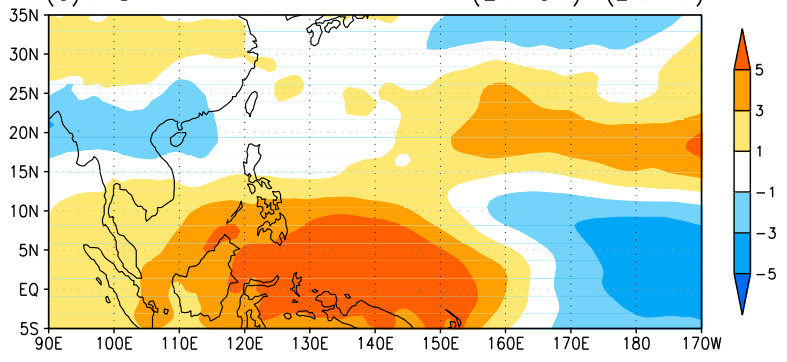

FIG. 4. Composite $P_{\text {TCG }}$ patterns for (a) El Niño-active MJO phases and (b) La Niña-inactive MJO phases. Composite differences $(\mathrm{EN}-\mathrm{aM}-\mathrm{LN}-\mathrm{iM})$ of (c) 850 -hPa relative vorticity and flow, (d) 700-hPa relative humidity, and (e) vertical wind shear of total winds. Units are $\mathrm{s}^{-1}$ in (c), \% in (d), and $\mathrm{m} \mathrm{s}^{-1}$ in (e).
FIG. 5. Composite $P_{\text {TCG }}$ patterns for (a) the positive-vorticity ERW and (b) the negative-vorticity ERW.

\section{Relative influence of ENSO, MJO, and ERW on TC genesis and their combined effects}

Summarizing the results discussed in previous sections, we compare the relative influence of climate oscillations on TC genesis by comparing occurrence of $\mathrm{TC}_{d}$ and $\mathrm{TC}_{n}$ in favorable and unfavorable environment caused by interannual and intraseasonal oscillations. To compare their relative influences, the $\mathrm{TC}_{d}$ and $\mathrm{TC}_{n}$ numbers are all normalized to show the values per 100 days over the whole NWP domain as shown in Fig. 7. The numbers of $\mathrm{TC}_{d}$ and $\mathrm{TC}_{n}$ in the figure can be summed to show the respective mean number of PTD $\left(\mathrm{TC}_{d}+\mathrm{TC}_{n}\right)$ for El Niño and La Niña, the active and inactive MJO, and the pvERW and nvERW types that are about the same, $\sim 31$ per 100 days per whole WNP domain. ERWs appear to be more effective on the influence of TC genesis as shown by the $P_{\text {TCG }}$ that is $0.43 /$ 0.25 for the pvERW/nvERW type as compared with the $P_{\text {TCG }}$ for El Niño/La Niña and the active/inactive MJO that is about $0.4 / 0.3$ and $0.42 / 0.32$, respectively. This result indicates that negative vorticity of ERWs has stronger inhibition effects on TC genesis than La Niña and the inactive MJO do. Negative vorticity of ERWs is particularly effective in lowering $P_{\mathrm{TCG}}$ in the western NWP west of $150^{\circ} \mathrm{E}$ as shown in Fig. 5, while positive vorticity of ERWs promotes $P_{\text {TCG }}$ to be higher than the climatology over most parts of the WNP relative to the spatial distribution of $P_{\mathrm{TCG}}$ for El Niño (Fig. 2a) and the active MJO (Fig. 3a). This is likely due to a stronger vorticity in the pvERW type than that in El Niño and the 
(a)DIV150 V150

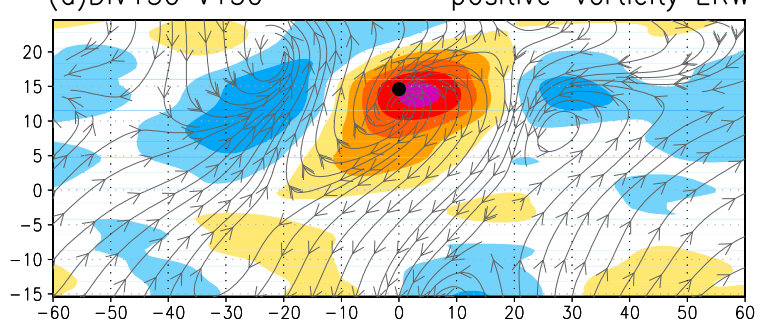

(b)V0R850 V850

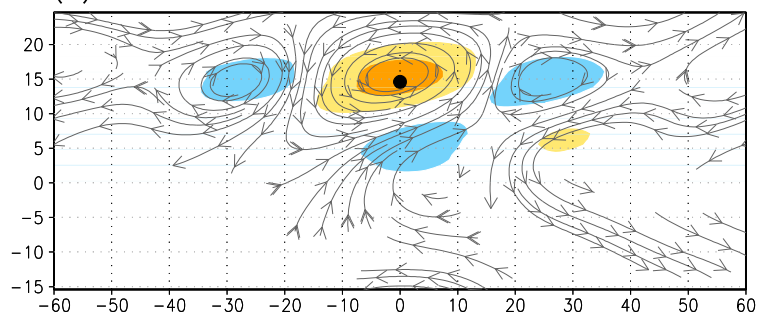

(c)OLR V850

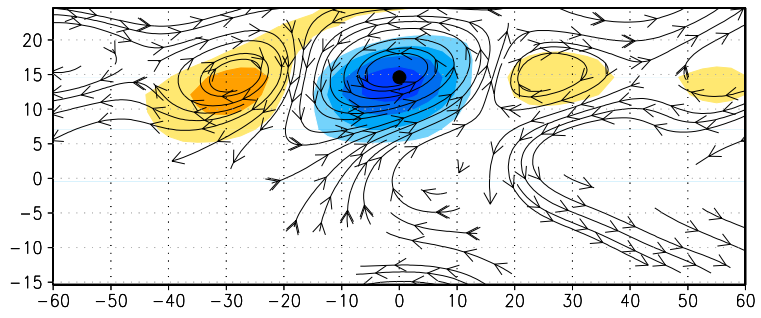

(d)DIV150 V150

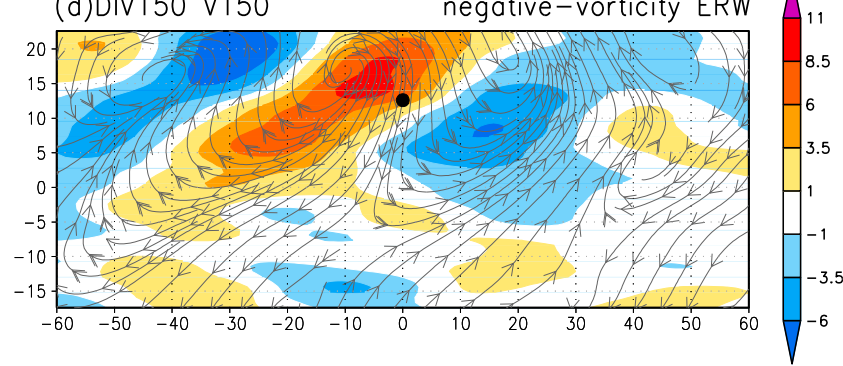

(e)VOR850 V850

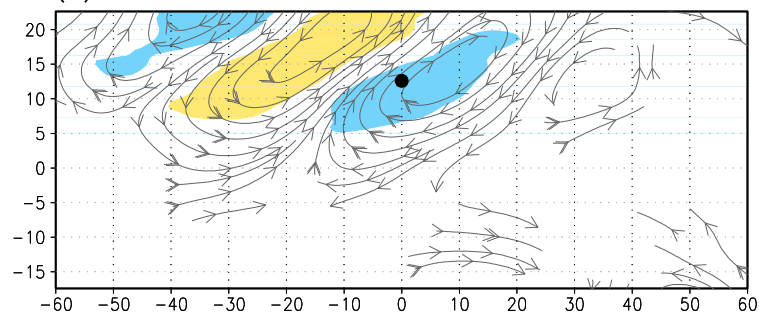

(f)OLR V850

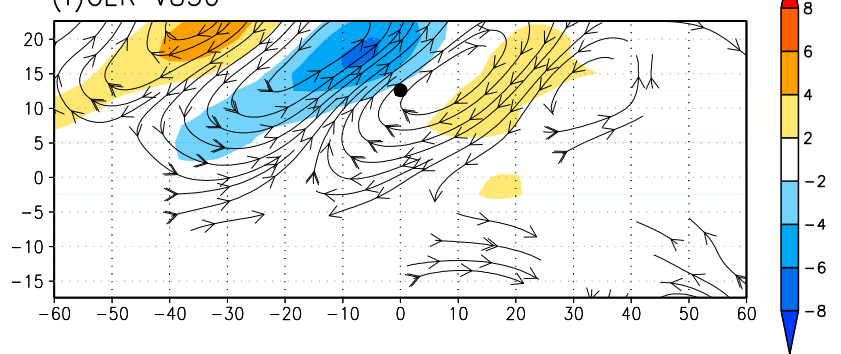

FIG. 6. Composite structure for ERWs relative to all $\mathrm{TC}_{d}$ centers: (a) divergence and streamline at $150 \mathrm{hPa}$, (b) vorticity and streamline at $850 \mathrm{hPa}$, and (c) OLR and $850-\mathrm{hPa}$ streamline, all for the positive-vorticity ERW. (d)-(f) As in (a)-(c), but for the negativevorticity ERW.

active MJO because a domain of influence by ERWs is a fraction of the western Pacific warming pool while that of ENSO and the MJO is the whole warm pool.

The combined effect of interannual and intraseasonal oscillations on TC genesis is shown by $P_{\mathrm{TCG}}$ in Table 3 under different combined environments. Based on eight combinations of the two phases of each of the three oscillations (ENSO, the MJO, ERWs), we divide the large-scale environments into four groups: most favorable environment (El Niño, the active MJO, pvERW), most unfavorable environment (La Niña, the inactive MJO, nvERW), favorable environment (two favorable phases, one unfavorable phase), and unfavorable environment (one favorable phase, two unfavorable phases). The favorable environment can also include the group of the active MJO, pvERW in the normal years and the unfavorable environment can include the group of the inactive MJO, nvERW in the normal years. The two groups of the active MJO, nvERW and the inactive MJO, pvERW in the normal years are regarded as the normal environments. The most favorable and unfavorable environments produce the highest (0.56) and lowest (0.17) $P_{\text {TCG }}$ (values in bold and italic in Table 3), respectively. $P_{\mathrm{TCG}}$ for the favorable environments ranges from $0.33,0.44,0.49$, to 0.50 (bold values in Table 3 ) that

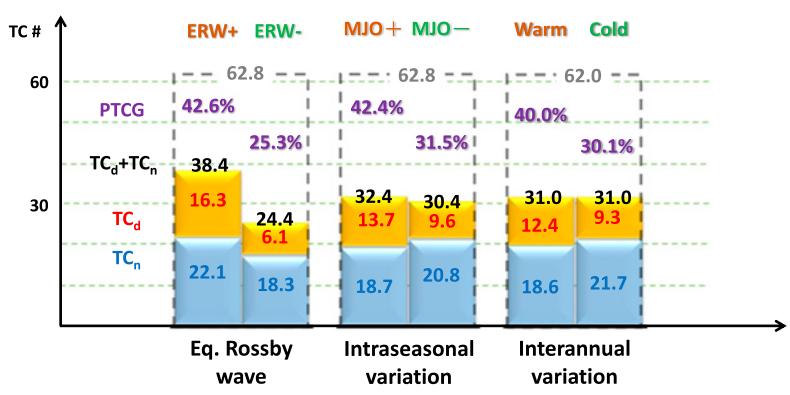

FIG. 7. $\mathrm{TC}_{d}$ and $\mathrm{TC}_{n}$ number per 100 days over the whole WNP domain for ENSO (warm plus cold), the MJO (active plus inactive), and ERWs (positive vorticity plus negative vorticity). The corresponding values of $P_{\mathrm{TCG}}$ are also shown. 
are generally higher than the climatology value of 0.36 . $P_{\mathrm{TCG}}$ for the unfavorable conditions ranges from 0.33 , $0.28,0.23$, to 0.22 (values in italic in Table 3) that are all below climatology. As mentioned already, the $P_{\mathrm{TCG}}$ value for the nvERW type (0.25) is notably lower than that for La Niña (0.30) and the inactive MJO (0.32).

\section{Conclusions}

The main purpose of this study is to better understand the influence of interannual (ENSO) and intraseasonal oscillations (the MJO, ERWs) on TC genesis based on the probability of a precursory tropical disturbance (PTD) developing into a TC in the WNP basin $\left(0^{\circ}-35^{\circ} \mathrm{N}\right.$, $100^{\circ} \mathrm{E}-170^{\circ} \mathrm{W}$ ) during $1990-2014$ warm seasons (MaySeptember). PTDs are identified by a vortex analysis of 3-8-day-filtered 850-hPa relative vorticity to search for PTDs with the following three criteria: 1) its maximum cyclonic relative vorticity at $850 \mathrm{hPa}$ reaches $10^{-5} \mathrm{~s}^{-1}, 2$ ) the maximum center reaching $10^{-5} \mathrm{~s}^{-1}$ has to exceed $16000 \mathrm{~km}^{2}$, and 3) the above two criteria have to be satisfied for 72 consecutive hours. Identified PTDs are further divided into two types: developing $\left(\mathrm{TC}_{d}\right)$ and nondeveloping $\left(\mathrm{TC}_{n}\right)$ cases into TCs. Productivity of TC genesis $\left(P_{\mathrm{TCG}}\right)$ is estimated by a value of $\mathrm{TC}_{d} /\left(\mathrm{TC}_{d}+\mathrm{TC}_{n}\right)$. Climatologically, there are $11.0 \mathrm{TC}_{d}$ cases and $20.1 \mathrm{TC}_{n}$ cases over the entire WNP basin in every 100 days during the warm seasons. The total PTD number $\left(\mathrm{TC}_{d}+\mathrm{TC}_{n}\right)$ is 31.1 and the climatological $P_{\mathrm{TCG}}$ value is 0.35 over the entire WNP basin.

The composite analyses for the warm and cold phases of ENSO and the active and inactive phases of the MJO all show a PTD number close to the climatological value. However, more $\mathrm{TC}_{d}$ cases occur in El Niño and the active MJO phases than La Niña and the inactive MJO phases, resulting in a lager $P_{\mathrm{TCG}}$ in El Niño (0.40) and the active MJO phases (0.42) than La Niña (0.30) and the inactive MJO phases $(0.32) . P_{\text {TCG }}$ patterns elongate southeastward from the SCS into the tropical WNP during El Niño years, but are confined to the western WNP during La Niña years. VOR850 anomaly is the key variable affecting the above $P_{\mathrm{TCG}}$ patterns. $P_{\mathrm{TCG}}$ patterns elongate eastward to the south of $15^{\circ} \mathrm{N}$ toward the eastern WNP in the active MJO phases, but to the north of $15^{\circ} \mathrm{N}$ in the inactive MJO phases. VOR850 causes higher $P_{\mathrm{TCG}}$ in the western WNP during the active phases, while reduced VWS enhances $P_{\mathrm{TCG}}$ in the northeastern parts of the WNP during the inactive phases. Combined ENSO-MJO conditions result in significantly increased (decreased) $P_{\mathrm{TCG}}$ in the $\mathrm{EN}-\mathrm{aM}(\mathrm{LN}-\mathrm{iM})$ phases as a result of them producing doubly positive (negative) effects. $P_{\mathrm{TCG}}$ is 0.46 for the $\mathrm{EN}-\mathrm{aM}$ phases and only 0.26 for the $\mathrm{LN}$-iM phases.
The contrasting $P_{\text {TCG }}$ patterns indicates that ENSO is more effective than the MJO in modulating $P_{\mathrm{TCG}}$ over the WNP basin. VOR850 and RH700 are the two leading variables affecting $P_{\mathrm{TCG}}$ patterns in these two phases.

The effect of ERWs on TC genesis is analyzed for $\mathrm{TC}_{d}$ and $\mathrm{TC}_{n}$ in two ERW types with positive vorticity (pvERW) or negative vorticity (nvERW) at $850 \mathrm{hPa}$ over a TC's center. Considering regions of cyclonic and anticyclonic flows in the WNP in any given day, numbers of $\mathrm{TC}_{d}, \mathrm{TC}_{n}$ normalized by fractional areas of the ERW types in the WNP per 100 days are 16.3, 22.1 for the pvERW type and 6.1, 18.3 for the nvERW type. Consequently, the $P_{\text {TCG }}$ value is 0.43 in the pvERW type and 0.25 in the nvERW type. Spatial distributions of $P_{\text {TCG }}$ show enhanced $P_{\text {TCG }}$ above climatology by the pvERW type over a broader area in the WNP than that of ENSO and the active MJO phases, and a significantly lower (higher) $P_{\mathrm{TCG}}$ in the western (eastern) part of the WNP separated by $150^{\circ} \mathrm{E}$. Composited ERW flows relative to $\mathrm{TC}_{d}$ and $\mathrm{TC}_{n}$ centers reveal two types of ERW flows with first baroclinic vertical structure: an asymmetric twin cyclone (anticyclonic) wave train with the northern portion (north of $10^{\circ} \mathrm{N}$ ) stronger than the southern portion of the wave train; a SW-NE-oriented cyclonic and anticyclonic circulation. In the pvERW flow, PTDs tend to develop into $\mathrm{TC}_{d}$ in the center of a low-level cyclonic circulation if convection-wave coupling is strong, while those PTDs in the center of a low-level anticyclonic circulation are more likely to decay as $\mathrm{TC}_{n}$. In the nvERW flow, a TC center (convection) appears to shift $1 / 4$ wavelength eastward of the low-level cyclonic center.

The combined ENSO-MJO-ERW impacts on TC genesis and $P_{\mathrm{TCG}}$ are shown in four different environments based on the 12 combinations of El Niño, La Niña $\times$ aMJO, iMJO $\times$ pvERW, nvERW and aMJO, $\mathrm{iMJO} \times$ pvERW, nvERW in the normal years. The most favorable and unfavorable environments correspond to triple positive (El Niño, aMJO, pvERW) and triple negative (La Niña, iMJO, nvERW) phases. The $P_{\text {TCG }}$ value is 0.56 and 0.17 , respectively. Favorable and unfavorable environments are further defined for more positive and more negative phases of the remaining combinations, except two normal combinations of aMJO, nvERW and iMJO, pvERW in the normal years. The $P_{\text {TCG }}$ values range from 0.33 to 0.50 for favorable environments and from 0.22 to 0.33 for unfavorable environments. The result also suggests that ENSO is more effective than the MJO in modulating spatial patterns of $P_{\mathrm{TCG}}$ over the WNP basin, yet ERWs are the most effective in regulating TC genesis, especially in the negative vorticity type. 
For the entire WNP basin, TC genesis productivity appears to be primarily modulated by dynamic variable such as $850-\mathrm{hPa}$ relative vorticity. This is consistent with the previous findings of $\mathrm{Fu}$ et al. (2012) and Hennon et al. (2013). TC genesis productivity in the WNP analyzed with a vortex analysis in this study show some different features from Teng et al. (2014) using a TCC analysis. Their $P_{\mathrm{TCG}}$ does not vary closely with ENSO. Our analysis shows a higher productivity during El Niño years and a lower productivity during La Niña years. Both Teng et al. (2014) and the present study show that total disturbance numbers between El Niño and La Niña years are comparable. Different $P_{\mathrm{TCG}}$ values are mainly due to a difference in detected TC numbers. The disturbance has to last for $72 \mathrm{~h}$ in our study, but only $24 \mathrm{~h}$ in Teng et al. (2014). This may lead to a better chance for TC genesis in our study, yielding a different ratio in genesis productivity under ENSO environments between these two studies.

Acknowledgments. The authors thank the anonymous reviewers for their valuable comments to improve the quality of this paper. This study was supported by the Minister of Science and Technology, Taiwan, under Grants MOST 105-2119-M-002-025, MOST 103-2111M-022-002-MY3, and MOST 104-2111-M-845-001.

\section{REFERENCES}

Barrett, B. S., and L. M. Leslie, 2009: Links between tropical cyclone activity and Madden-Julian oscillation phase in the North Atlantic and northeast Pacific basins. Mon. Wea. Rev., 137, 727-744, https://doi.org/10.1175/2008MWR2602.1.

Camargo, S. J., A. W. Robertson, S. J. Gaffney, P. Smyth, and M. Ghil, 2007: Cluster analysis of typhoon tracks. Part I: General properties. J. Climate, 20, 3635-3653, https://doi.org/ 10.1175/JCLI4188.1.

Chan, J. C. L., 1985: Tropical cyclone activity in the northwest Pacific in relation to the El Niño/Southern Oscillation phenomenon. Mon. Wea. Rev., 113, 599-606, https://doi.org/ 10.1175/1520-0493(1985)113<0599:TCAITN>2.0.CO;2.

- 2000: Tropical cyclone activity over the western North Pacific associated with El Niño and La Niña events. J. Climate, 13, 2960-2972, https://doi.org/10.1175/1520-0442(2000)013<2960: TCAOTW $>2.0 . \mathrm{CO} ; 2$.

Chatterjee, P., and B. N. Goswami, 2004: Structure, genesis and scale selection of the tropical quasi-biweekly mode. Quart. J. Roy. Meteor. Soc., 130, 1171-1194, https://doi.org/10.1256/ qj.03.133.

Chen, G., and C.-H. Sui, 2010: Characteristics and origin of quasibiweekly oscillation over the western North Pacific during boreal summer. J. Geophys. Res., 115, D14113, https://doi.org/ 10.1029/2009JD013389.

—_, and C. Chou, 2014: Joint contribution of multiple equatorial waves to tropical cyclogenesis over the western North Pacific. Mon. Wea. Rev., 142, 79-93, https://doi.org/10.1175/MWR-D-13-00207.1.

Chen, T.-C., S.-Y. Wang, and M.-C. Yen, 2006: Interannual variation of the tropical cyclone activity over the western North
Pacific. J. Climate, 19, 5709-5720, https://doi.org/10.1175/ JCLI3934.1.

Chia, H. H., and C. F. Ropelewski, 2002: The interannual variability in the genesis location of tropical cyclones in the northwest Pacific. J. Climate, 15, 2934-2944, https://doi.org/ 10.1175/1520-0442(2002)015<2934:TIVITG>2.0.CO;2.

Ching, L., C.-H. Sui, and M.-J. Yang, 2010: An analysis of the multiscale nature of tropical cyclone activities in June 2004: Climate background. J. Geophys. Res., 115, D24108, https:// doi.org/10.1029/2010JD013803.

,,,--- and P.-L. Lin, 2015: A modeling study on the effects of MJO and equatorial Rossby waves on tropical cyclone genesis over the western North Pacific in June 2004. Dyn. Atmos. Oceans, 72, 70-87, https://doi.org/10.1016/ j.dynatmoce.2015.10.002.

Chung, P.-H., and T. Li, 2015: Characteristics of tropical cyclone genesis in the western North Pacific during the developing and decaying phases of two types of El Niño. J. Trop. Meteor., 21, 14-22.

Dee, D. P., and Coauthors, 2011: The ERA-Interim Reanalysis: Configuration and performance of the data assimilation system. Quart. J. Roy. Meteor. Soc., 137, 553-597, https://doi.org/ 10.1002/qj.828.

Dong, K., 1988: El Niño and tropical cyclone frequency in the Australian region and the northwest Pacific. Aust. Meteor. Mag., 36, 219-255.

Frank, W. M., and P. E. Roundy, 2006: The role of tropical waves in tropical cyclogenesis. Mon. Wea. Rev., 134, 2397-2417, https:// doi.org/10.1175/MWR3204.1.

Fu, B., T. Li, M. S. Peng, and F. Weng, 2007: Analysis of tropical cyclogenesis in the western North Pacific for 2000 and 2001. Wea. Forecasting, 22, 763-780, https://doi.org/10.1175/ WAF1013.1.

—, M. S. Peng, T. Li, and D. E. Stevens, 2012: Developing versus nondeveloping disturbances for tropical cyclone formation. Part II: Western North Pacific. Mon. Wea. Rev., 140, 10671080, https://doi.org/10.1175/2011MWR3618.1.

Gall, J. S., and W. M. Frank, 2010: The role of equatorial Rossby waves in tropical cyclogenesis. Part II: Idealized simulations in a monsoon trough environment. Mon. Wea. Rev., 138, 13831398, https://doi.org/10.1175/2009MWR3115.1.

Gray, W. M., 1968: Global view of the origin of tropical disturbances and storms. Mon. Wea. Rev., 96, 669-700, https://doi.org/ 10.1175/1520-0493(1968)096<0669:GVOTOO $>2.0 . C O ; 2$.

Hall, J. D., A. J. Matthews, and D. J. Karoly, 2001: The modulation of tropical cyclone activity in the Australian region by the MaddenJulian oscillation. Mon. Wea. Rev., 129, 2970-2982, https://doi.org/ 10.1175/1520-0493(2001)129<2970:TMOTCA > 2.0.CO;2.

Hennon, C. C., C. N. Helms, K. R. Knapp, and A. R. Bowen, 2011: An objective algorithm for detecting and tracking tropical cloud clusters: Implications of tropical cyclogenesis prediction. J. Atmos. Oceanic Technol., 28, 1007-1018, https://doi.org/ 10.1175/2010JTECHA1522.1.

— , and Coauthors, 2013: Tropical cloud cluster climatology, variability, and genesis productivity. J. Climate, 26, 3046-3066, https://doi.org/10.1175/JCLI-D-12-00387.1.

Huang, P., C. Chou, and R. Huang, 2011: Seasonal modulation of tropical intraseasonal oscillations on tropical cyclone geneses in the western North Pacific. J. Climate, 24, 6339-6352, https:// doi.org/10.1175/2011JCLI4200.1.

Kikuchi, K., and B. Wang, 2009: Global perspective of the quasibiweekly oscillation. J. Climate, 22, 1340-1359, https://doi.org/ 10.1175/2008JCLI2368.1. 
Kim, H.-M., M.-I. Lee, P. J. Webster, D. Kim, and J. H. Yoo, 2013 A physical basis for the probabilistic prediction of the accumulated tropical cyclone kinetic energy in the western North Pacific. J. Climate, 26, 7981-7991, https://doi.org/10.1175/ JCLI-D-12-00679.1.

Kim, J.-H., C.-H. Ho, H.-S. Kim, C.-H. Sui, and S. K. Park, 2008: Systematic variation of summertime tropical cyclone activity in the western North Pacific in relation to the Madden-Julian oscillation. J. Climate, 21, 1171-1191, https://doi.org/10.1175/ 2007JCLI1493.1.

Klotzbach, P. J., 2014: The Madden-Julian oscillation's impacts on worldwide tropical cyclone activity. J. Climate, 27, 2317-2330, https://doi.org/10.1175/JCLI-D-13-00483.1.

Lander, M. A., 1994: An exploratory analysis of the relationship between tropical storm formation in the western North Pacific and ENSO. Mon. Wea. Rev., 122, 636-651, https://doi.org/ 10.1175/1520-0493(1994)122<0636:AEAOTR > 2.0.CO;2.

_ 1996: Specific tropical cyclone track types and unusual tropical cyclone motions associated with a reverse-oriented monsoon trough in the western North Pacific. Wea. Forecasting, 11, 170-186, https://doi.org/10.1175/1520-0434(1996)011<0170: STCTTA $>2.0 . C O ; 2$.

Lau, K.-H., and N.-C. Lau, 1990: Observed structure and propagation characteristics of tropical summertime synoptic scale disturbances. Mon. Wea. Rev., 118, 1888-1913, https://doi.org/ 10.1175/1520-0493(1990)118<1888:OSAPCO >2.0.CO;2.

Li, C., 1988: Actions of typhoons over the western Pacific (including the South China Sea) and El Niño. Adv. Atmos. Sci., $\mathbf{5}$, 107-115, https://doi.org/10.1007/BF02657352.

Li, R. C. Y., W. Zhou, J. C. L. Chan, and P. Huang, 2012: Asymmetric modulation of western North Pacific cyclogenesis by the Madden-Julian oscillation under ENSO conditions. J. Climate, 25, 5374-5385, https://doi.org/10.1175/JCLI-D-11-00337.1.

Liebmann, B., and C. A. Smith, 1996: Description of a complete (interpolated) outgoing longwave radiation dataset. Bull. Amer. Meteor. Soc., 77, 1275-1277, https://doi.org/10.1175/ 1520-0477-77.6.1274.

_ , H. H. Hendon, and J. D. Glick, 1994: The relationship between tropical cyclones of the western Pacific and Indian Oceans and the Madden-Julian oscillation. J. Meteor. Soc. Japan, 72, 401-411, https://doi.org/10.2151/jmsj1965.72.3_401.

Madden, R. A., and P. R. Julian, 1971: Detection of a 40-50 day oscillation in the zonal wind in the tropical Pacific. J. Atmos. Sci. 28, 702-708, https://doi.org/10.1175/1520-0469(1971)028<0702 DOADOI $>2.0 . \mathrm{CO} ; 2$.

— and - 1972: Description of global-scale circulation cells in the Tropics with a 40-50 day period. J. Atmos. Sci., 29, 1109-1123, https://doi.org/10.1175/1520-0469(1972)029<1109: DOGSCC $>2.0 . \mathrm{CO} ; 2$.

— , and 1994: Observations of the 40-50-day tropical oscillation-A review. Mon. Wea. Rev., 122, 814-837, https:// doi.org/10.1175/1520-0493(1994)122<0814:OOTDTO >2.0.CO;2.

Masunaga, H., 2007: Seasonality and regionality of the MaddenJulian oscillation, Kelvin wave, and equatorial Rossby wave. J. Atmos. Sci., 64, 4400-4416, https://doi.org/10.1175/ 2007JAS2179.1.

McBride, J. L., 1995: Tropical cyclone formation: Global perspectives on tropical cyclones. WMO/TD-693, World Meteorological Organization, 63-105.

Molinari, J., and D. Vollaro, 2013: What percentage of western North Pacific tropical cyclones form within the monsoon trough? Mon. Wea. Rev., 141, 499-505, https://doi.org/10.1175/ MWR-D-12-00165.1.
Peng, M. S., B. Fu, T. Li, and D. E. Stevens, 2012: Developing versus nondeveloping disturbances for tropical cyclone formation. Part I: North Atlantic. Mon. Wea. Rev., 140, 10471066, https://doi.org/10.1175/2011MWR3617.1.

Philander, S. G. H., 1990: El Niño, La Niña and the Southern Oscillation. Academic Press, $289 \mathrm{pp}$.

Rasmusson, E. M., and T. H. Carpenter, 1982: Variations in tropical sea surface temperature and surface wind fields associated with the Southern Oscillation/El Niño. Mon. Wea. Rev., 110, 354-384, https:// doi.org/10.1175/1520-0493(1982)110<0354:VITSST>2.0.CO;2. , and J. M. Wallace, 1983: Meteorological aspects of the El Niño/Southern Oscillation. Science, 222, 1195-1202, https:// doi.org/10.1126/science.222.4629.1195.

Ritchie, E. A., and G. J. Holland, 1999: Large-scale patterns associated with tropical cyclogenesis in the western Pacific. Mon. Wea. Rev., 127, 2027-2043, https://doi.org/10.1175/ 1520-0493(1999)127<2027:LSPAWT>2.0.CO;2.

Schreck, C. J., and J. Molinari, 2009: A case study of an outbreak of twin tropical cyclones. Mon. Wea. Rev., 137, 863-875, https:// doi.org/10.1175/2008MWR2541.1.

Tao, L., L. Wu, Y. Wang, and J. Yang, 2012: Influence of tropical Indian Ocean warming and ENSO on tropical cyclone activity over the western North Pacific. J. Meteor. Soc. Japan, 90, 127144, https://doi.org/10.2151/jmsj.2012-107.

Teng, H.-F., C.-S. Lee, and H.-H. Hsu, 2014: Influence of ENSO on formation of tropical cloud clusters and their development into tropical cyclones in the western North Pacific. Geophys. Res. Lett., 41, 9120-9126, https://doi.org/10.1002/2014GL061823.

Wang, B., and J. C. L. Chan, 2002: How strong ENSO events affect tropical storm activity over the western North Pacific. J. Climate, 15, 1643-1658, https://doi.org/10.1175/1520-0442(2002)015<1643: HSEEAT $>2.0 . \mathrm{CO} ; 2$.

Wang, C., C. Li, M. Mu, and W. Duan, 2013: Seasonal modulations of different impacts of two types of ENSO events on tropical cyclone activity in the western North Pacific. Climate Dyn., 40, 2887-2902, https://doi.org/10.1007/s00382-012-1434-9.

Wheeler, M., and G. N. Kiladis, 1999: Convectively coupled equatorial waves: Analysis of clouds and temperature in the wavenumberfrequency domain. J. Atmos. Sci., 56, 374-399, https://doi.org/ 10.1175/1520-0469(1999)056<0374:CCEWAO>2.0.CO;2.

- and H. H. Hendon, 2004: An all-season real-time multivariate MJO index: Development of an index for monitoring and prediction. Mon. Wea. Rev., 132, 1917-1932, https://doi.org/ 10.1175/1520-0493(2004)132<1917:AARMMI>2.0.CO;2.

Wu, G., and N.-C. Lau, 1992: A GCM simulation of the relationship between tropical storm formation and ENSO. Mon. Wea. Rev., 120, 958-977, https://doi.org/10.1175/1520-0493(1992)120<0958: AGSOTR $>2.0 . \mathrm{CO} ; 2$.

Wu, L., Z. Wen, R. Huang, and R. Wu, 2012: Possible linkage between the monsoon trough variability and the tropical cyclone activity over the western North Pacific. Mon. Wea. Rev., 140, 140-150, https://doi.org/10.1175/MWR-D-11-00078.1.

Xie, X., and B. Wang, 1996: Low-frequency equatorial waves in vertically sheared zonal flow. Part II: Unstable waves. J. Atmos. Sci., 53, 3589-3605, https://doi.org/10.1175/1520-0469(1996)053<3589: LFEWIV $>2.0 . C O ; 2$.

Xue, Y., T. M. Smith, and R. W. Reynolds, 2003: Interdecadal changes of 30-yr SST normals during 1871-2000. J. Climate, 16, 1601-1612, https://doi.org/10.1175/1520-0442-16.10.1601.

Yoshida, R., and H. Ishikawa, 2013: Environmental factors contributing to tropical cyclone genesis over the western North Pacific. Mon. Wea. Rev., 141, 451-467, https://doi.org/10.1175/ MWR-D-11-00309.1. 
